\title{
Ege Üniversitesi Hastanesi veri tabanında meme kanseri hastalarının epidemiyolojisi ve genel sağ kalım özellikleri
}

\section{Epidemiological and overall survival characteristics of breast cancer patients in Ege University Hospital database}

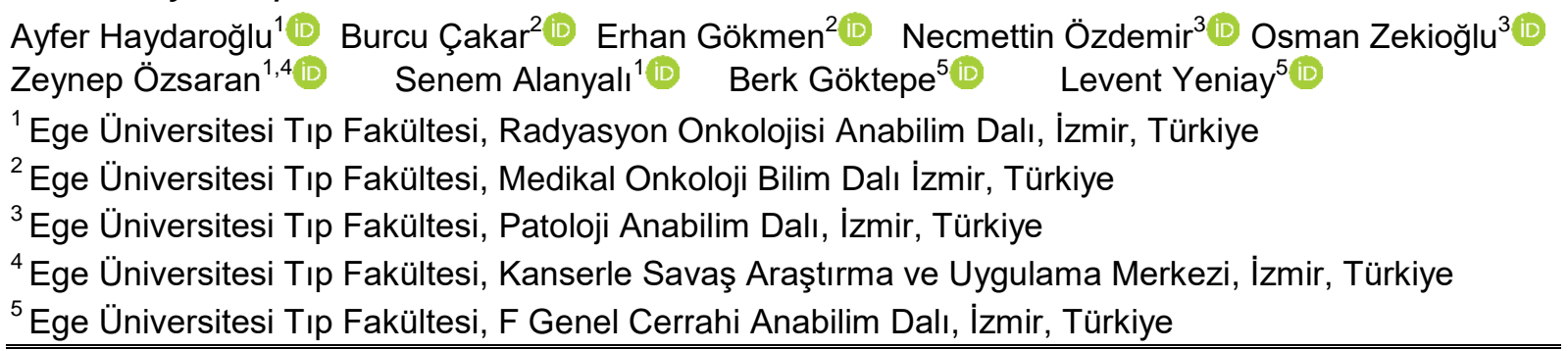

\section{Öz}

Amaç: Ege Üniversitesi Hastanesinde 1992-2017 arası kanser tanı ve tedavisi yapılan 13079 meme kanser tanılı hastanın genel özellikleri, tedavi modaliteleri ve sağ kalım sürelerinin tanımlanması amaçlanmıştır.

Gereç ve Yöntem: Ege Üniversitesi Kanserle Savaş Araştırma ve Uygulama Merkezi tarafından toplanan meme kanseri verileri CANREG özel bilgisayar programına kayıt edilmiş, DSÖ ve SEER sistemleri temelinde gruplanarak analizler yapılmıştır. İstatistik analizlerde Ki-kare, General Linear Model, Kaplan Meier sağ kalım analizleri uygulanmıştır. Kaplan Meier Sağ kalım analizinde Log Rank (Mantel-Cox), Breslow (Generalized Wilcoxon) ve Tarone-Ware istatistikleri kullanılmıştır. İstatistik analizlerde $p<0,05$ istatistiksel olarak anlamlı kabul edilmiştir

Bulgular: 13079 meme kanser tanılı hasta verisi analiz edilmiştir. Meme kanseri(MK) olgularımızın \%98,7'si kadın, \%1,3'ü erkektir. Olgularımızın en sık görüldüğü yaşlar kadınlarda 40-49 yaşlarda, erkeklerde ise 60-69 yaş aralığındadır. Kadın olgularımızda tanı anındaki görülme yaşları erkek olgulara göre daha genç yaşlardadır. Meme kanserli olgularımızda en sık yerleşim üst-dış kadranda (\%46), en sık histolojik alt tip invaziv duktal kanser $(\% 57,3)$ olarak izlenmiştir. Hastaların yaklaşık yarısı lokal ileri dönemde tanı almaktadır. Denovo metastatik hastalık erkeklerde \%17,7 iken kadınlarda bu oran \%8,4 dür. Evrelere göre beş ve 10 yıllık GSK sırasıyla; Lokalize kanserlerde \%94,1 ve $\% 86,6$, Lokal ileri evrede ise $\% 85,5$ ve $\% 71,1$, metastatik dönemde ise $\% 39,1$ ve $\% 22,7$ 'dir. Tüm evreler birlikte değerlendirildiğinde kadınlarda 5 ve 10 yıllık sağ kalımlar \%85,4 ve \%77,4 iken erkeklerde bu oranlar \%74,3 ve \%63'e düşmektedir.

Sonuç: EÜ Hastane Tabanlı Kanser Kayıt sisteminde kadın kanserlerinin dörtte birini meme kanserleri oluşturmaktadır. Bizim 13079 olgu içeren serimiz tek merkez olarak Türkiye'deki en geniş meme kanseri serisidir. Kadın olgularımızda meme kanseri erkek cinsiyete göre daha erken yaşta izlenmektedir ve daha iyi sağ kalımla ilişkilidir.

Anahtar Sözcükler: Meme kanseri, epidemiyoloji, insidans, mortalite, genel sağ kalım.

\section{Abstract}

Aim: The study aimed to define the baseline characteristics, treatment modalities and survival outcome of breast cancer patients who admitted to Ege University School of Medicine between 1992 2017.

\footnotetext{
Yazışma Adresi: Ayfer Haydaroğlu

Ege Üniversitesi Tıp Fakültesi, Radyasyon Onkolojisi

Anabilim Dalı, İzmir, Türkiye

E-mail: haydaroglua@gmail.com
} 
Materials and Methods: The breast cancer patients' data that was collected by Ege University Cancer Research Center, was recorded to CANREG computer program, and analyses was performed according to WHO and SEER system definitions. Chi-square, General Linear Model and Kaplan-Meier survival analyses was performed for further analyses. Log Rank (Mantel-Cox), Breslow (Generalized Wilcoxon) and Tarone-Ware statistics was used for survival analyses. $p<0.05$ was considered as statistically significant.

Results: The 13079 breast cancer patients' data was analyzed. 98.7\% of the patients were female and $1.3 \%$ was male in gender. The most common age interval in diagnosis was 40-49 years in women and 60-69 years in men. The female patients initial age at diagnosis was younger than male patients. The most common localization of the primary tumor was upper-outer quadrant (46\%) and the most common histology was detected as invasive ductal carcinoma (57.3\%). Nearly half of breast cancer patients were diagnosed in locally advanced setting. The denovo metastatic disease frequency was $17.7 \%$ in women and $8.4 \%$ in men. The 5 - and 10-year overall survival in female and male patients was $94.1 \%$ and $86.6 \%$ in localized disease, $85.5 \%$ and $71.1 \%$ in locally advanced setting and $39.1 \%$ and $22.7 \%$ in metastatic setting respectively. When all stage groups were analyzed together, the 5and 10 -year survival was found $85.4 \%$ and $77.4 \%$ in women and $74.3 \%$ and $63 \%$ in men.

Conclusion: The data that is presented in this article is the largest dataset that has been reported in Turkey. Breast cancer is composed of 1 of 4 all-female cancers in our dataset. The female patients are diagnosed in earlier ages than men and demonstrate better prognosis.

Keywords: Breast cancer, epidemiology, incidence, mortality, overall survival.

\section{Giriş}

Meme Kanseri kadınlarda en sık görülen kanser türüdür. Dünya genelinde kanser tanısı alan dört kadından biri meme kanseridir ve 100'den fazla ülkede kadınlarda kanser ölümlerinde birinci sıradadır. İstisna olarak Kuzey Amerika ve Avrupa ülkelerinde akciğer kanseri, bazı Afrika ülkelerinde ise serviks uteri kanseri kanser mortalitesinde birinci sırada yer alır (1). Meme kanseri rölatif olarak daha iyi prognozu olması nedeniyle, kansere bağlı ölümlerde beşinci sırada yer almaktadır. Gelişmiş, ülkelerde meme kanseri insidansının yüksek olmasını, yaşam standartlarının yüksek olması, erken menarş yaşı, geç gebelik ve doğum, daha az sayıda gebelik, hormon replasman tedavisi (HRT) kullanımı gibi artmış risk faktörlerine ve mamografi gibi tekniklerin kullanılmasıyla erken tanının mümkün olması ve kayıt sistemlerinin yeterli ve daha etkili olmasına bağlamak olasıdır. Meme kanseri (MK) hızları tüm dünyada özellikle gelişmekte olan ülkelerde ciddi artışlar göstermekle beraber özellikle son 10 yılda pek çok gelişmiş, ülkede Menopozda HRT kullanımının azalmasına, uzun süreli emzirme teşvikine bağlı olarak düşme eğilimi gösterdiği gözlenmektedir (1-3). Gelişmekte olan ülkeler, Doğu Avrupa ülkeleri, Asya, Latin Amerika ülkelerinde gözlenen artışların batılı beslenme alışkanlıklarındaki artıştan kaynaklanabileceği düşünülmektedir (1). Meme kanseri insidansı diğer risk faktörleri yanı sıra en çok yaşla ilişkili bulunmaktadır. Meme kanseri görülmesi aktif üreme yaşlarının sonuna doğru 40-50 yaşlarda hızı ı artış ve 50 yaş civarı menopoz sonrası hafif bir düşüş göstermektedir (4). Meme kanserinin sıklığı ve mortalitesinin nispeten azlığı prevalansı en yüksek kanser türü olmasına neden olmaktadır (5).

$\mathrm{Bu}$ retrospektif araştırma makalesi etik onay alınarak multidisipliner katkıyla hazırlanmış olup EÜH'de 1992-2017 arası kanser tanı ve tedavisi yapılan 13079 meme kanserinin epidemiyolojik ve genel sağ kalım özellikleri araştırımış, sonuçlar kaynaklarla karşılaştırılmıştır.

\section{Gereç ve Yöntem}

EÜ Kanser Araştırma Merkezi (EÜKAM) tarafından 1992-2017 arası EÜH'de toplanan meme kanseri verileri CANREG özel bilgisayar programına kayıt edilmiştir. Bu veriler DSÖ ve SEER sistemleri temelinde gruplanarak analizler yapılmıştır. İstatistik analizlerde Kikare, General Linear Model (GLM), Kaplan Meier sağ kalım analizleri uygulanmıştır. Kaplan Meier sağ kalım analizinde Log Rank (Mantel-Cox), Breslow (Generalized Wilcoxon) ve Tarone-Ware istatistikleri kullanılmıştır. İstatistik analizlerde $p<0,05$ istatistiksel olarak anlamlı kabul edilmiştir.

\section{Bulgular}

EÜH Kanser veri sisteminde bulunan 117.139 olgu arasında meme kanseri \%11,5 $(n=13079)$ oranı ile dördüncü, kadınlarda ise birinci sırada 
$(\% 25,2)$ yer almaktadır. Hastanemizin kadın kanserlerinin yaklaşık dörtte biri meme kanseridir. MK olgularımızın 12909 (\%98,7) kadın, $170(\% 1,3)$ 'i ise erkektir. Olgularımızın en sık görüldüğü yaşlar kadınlarda 40-49 yaş aralığında, erkek meme kanserlerinde ise 6069 yaş aralığındadır (Tablo-1, Şekil-1).

Büyük çoğunluğu oluşturan kadın olgularımızda tanı anındaki görülme yaşları erkek olgulara göre daha genç yaşlardadır (Ki-kare $=67,756 ; p<0.001$ ) (Şekil-2). Meme kanserli olgularımızda en sık yerleşim üst-dış kadranda (\%46) bulunmaktadır (Şekil-3). Histolojik tanılarda ise invaziv duktal kanserler (IDK) en fazla görülmekte $(\% 57,3)$, bunu lobüler kanserler izlemektedir (Şekil-4).

Tablo-1.Meme kanserlerinde yaş gruplarına göre dağılım.

\begin{tabular}{ccc}
\hline Yaş Grubu & $\mathbf{N}$ & $\%$ \\
\hline $\mathbf{1 0 - 1 9}$ & 8 & 0.1 \\
$\mathbf{2 0 - 2 9}$ & 245 & 1.9 \\
$\mathbf{3 0 - 3 9}$ & 1831 & 14.0 \\
$\mathbf{4 0 - 4 9}$ & 3890 & 29.7 \\
$\mathbf{5 0 - 5 9}$ & 3496 & 26.7 \\
$\mathbf{6 0 - 6 9}$ & 2322 & 17.8 \\
$\mathbf{7 0 +}$ & 1287 & 9.8 \\
Toplam & 13079 & 100.0 \\
\hline
\end{tabular}

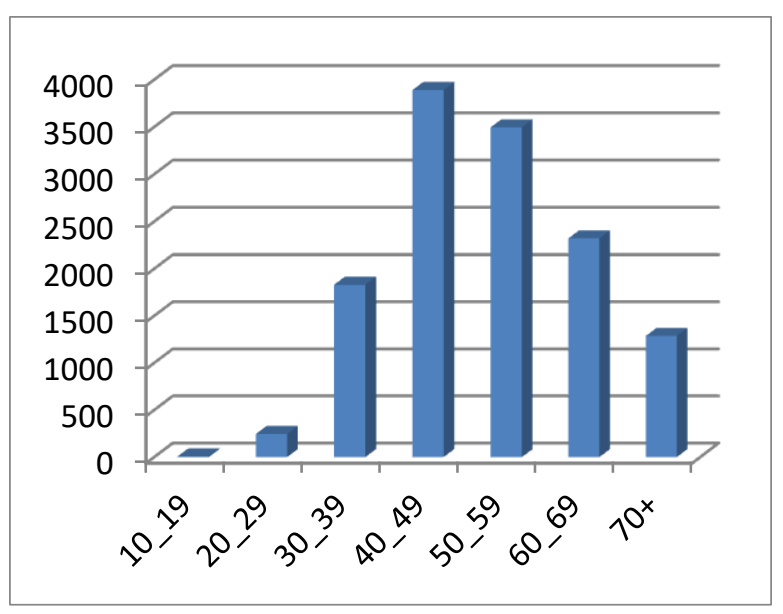

Şekil-1. Meme kanserlerinde yaş gruplarına göre dağılım grafiği.

Meme kanseri olgularımız çoğunlukla lokal ileri dönemde tanı almaktadır. Kadın cinsiyette erkek cinsiyete göre hastalık daha erken evrede görülmektedir. Metastatik evrede tanı erkeklerde \%17,7 iken kadınlarda bu oran \%8,4 dür (Ki-kare=17,630; $\quad \mathrm{p}<0,002) \quad($ Şekil-5). Hastanemizde meme kanserinde yıllara göre artış eğilimi görülmektedir ve bu artış istatistiksel olarak anlamlıdır (Şekil-6).

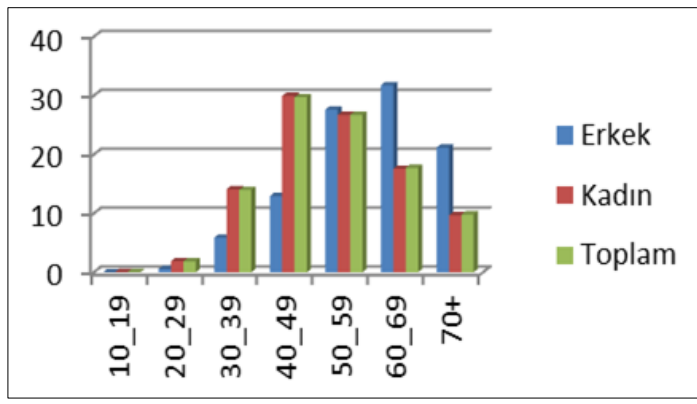

Şekil-2. Meme kanserlerinde cinsiyet ve yaş gruplarına göre dağılım grafiği.

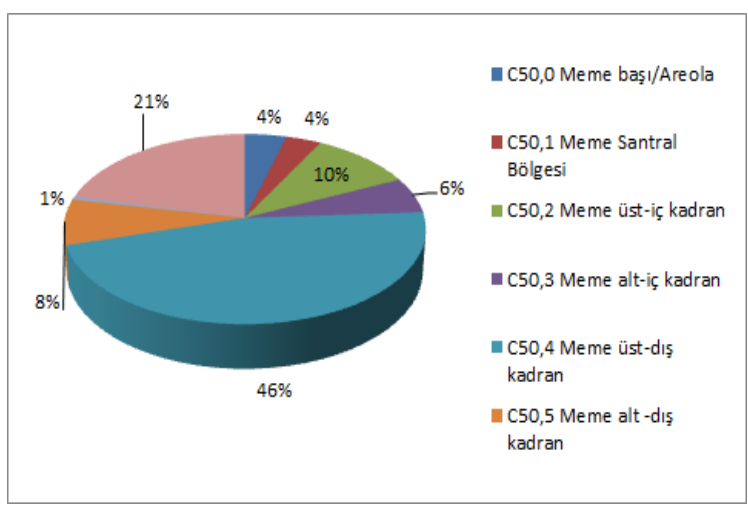

Şekil 3. Meme kanserlerinde yerleşim yerlerine göre dağılım.

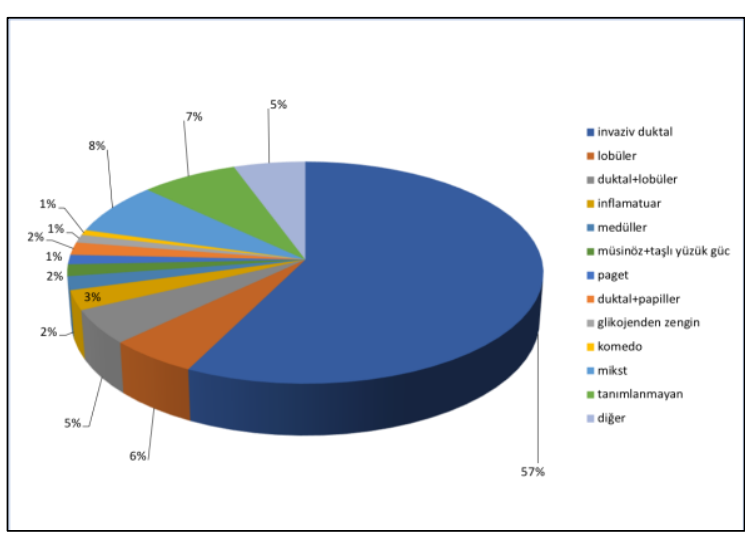

Şekil-4. Meme kanserlerinde histopatolojik tanılara göre dağılım.

Bu dünya verisi ile çelişen bir açıklama, tartışmada da literatürde metastatik hastalıkta en iyi sağ kalımın 50 yaş altı olduğunu belirtmişiz. MK'nin yaş gruplarına göre sağ kalım değerlendirildiğinde yaş grupları arasında heterojen bir dağılım olduğu görülmektedir. 70 yaş üstü grup en kötü ve 40 49 yaş grubu en iyi sağ kalımla ilişkili görülmüştür. En sık görülme yaş grubu olan 40-49 ay için beş yıllık GSK \%90 civarı bulunmuştur (Şekil-7). 


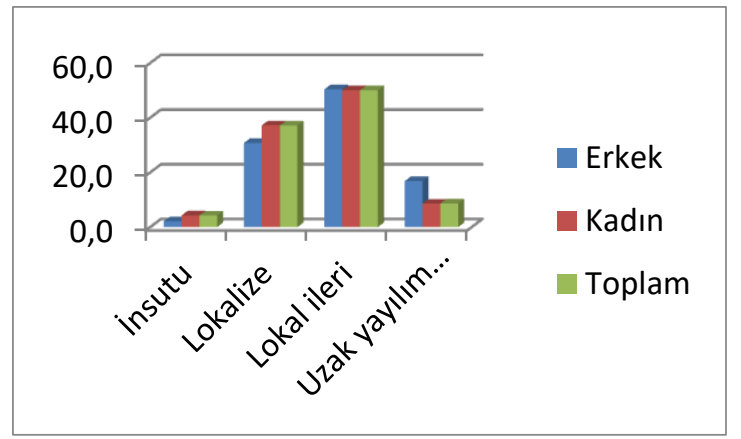

Şekil-5. Evre ve cinsiyete göre dağılım grafiği.

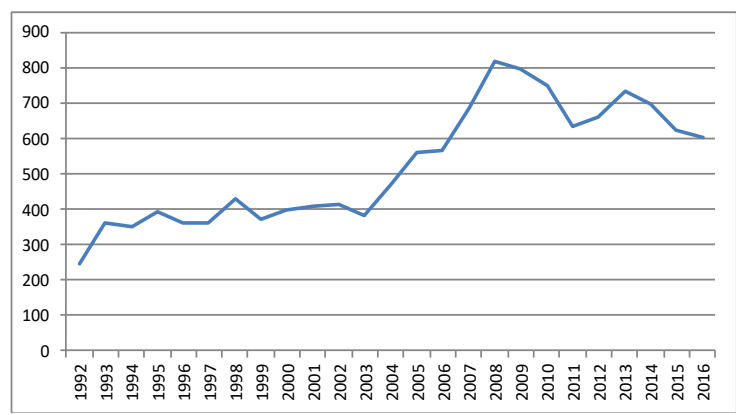

Şekil-6. Meme Kanserinde y göre dağılım tem eme Kanserinde y göre dağ.

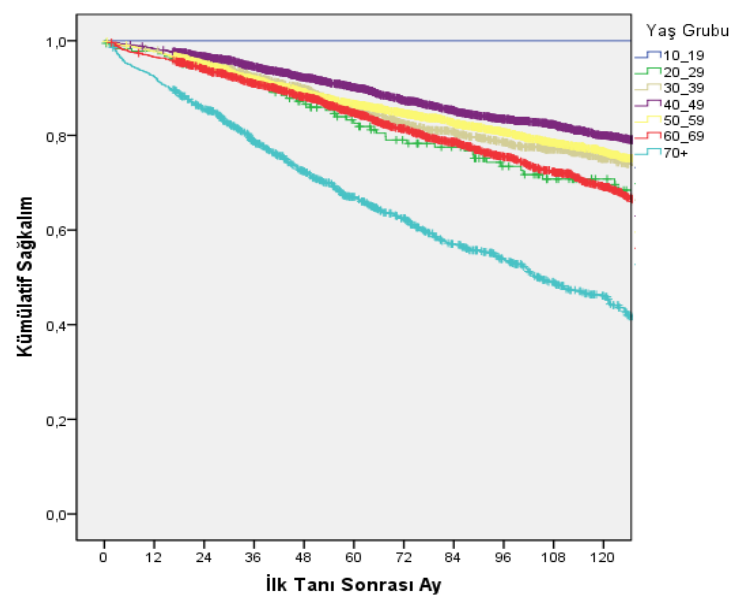

Şekil-7. Yaş gruplarına göre genel sağ kalım grafiği.

Histopatolojik tanılara göre sağ kalımda inflamatuar kanserler en kötü, kribriform ve tubuler kanserlerde sağ kalım en iyidir. On yıllık GSK'lar sırasıyla \%93,5 ve \%96'dır. En sık görülen invaziv duktal kanserlerde 5 ve 10 yıllık sağ kalımlar ise sırasıyla \%86,4 ve \%74,9 dur (Tablo-2, Şekil-8). Evrelere göre 5 ve 10 yıllık GSK sırasıyla; Lokalize kanserlerde $\% 94,1$ ve \%86,6, lokal ileri evrede \%85,5 ve $\% 71,1$, metastatik dönemde ise $\% 39,1$ ve \%22,7'dir (Tablo-3, Şekil-9).

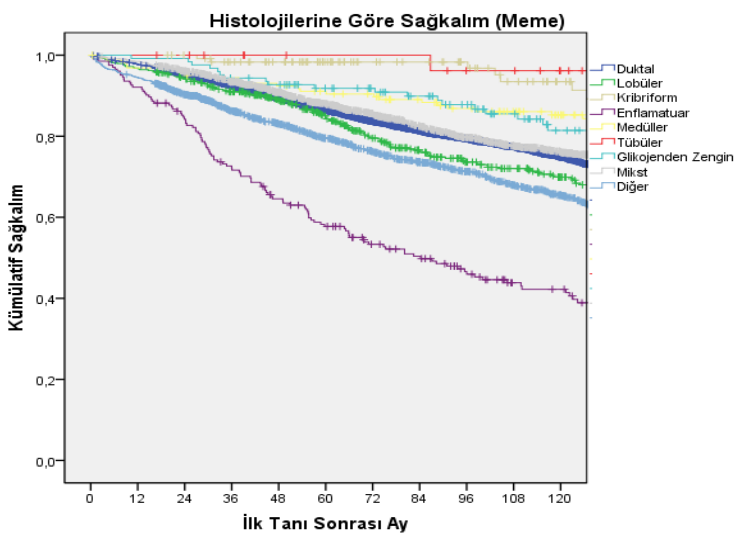

Şekil-8. Histopatolojik tanılara göre sağ kalım grafiği.

Tablo-2. Histopatolojik tanılara göre sağ kalım.

\begin{tabular}{|c|c|c|c|c|c|c|}
\hline \multirow{2}{*}{ Tedavi } & \multirow[b]{2}{*}{$\mathbf{N}$} & \multicolumn{2}{|c|}{ Yaşayan } & \multirow{2}{*}{$\begin{array}{c}2 \text { yıl } \\
\%\end{array}$} & \multirow{2}{*}{$\begin{array}{c}5 \text { yıl } \\
\%\end{array}$} & \multirow{2}{*}{$\begin{array}{c}10 \mathrm{yı} \\
\%\end{array}$} \\
\hline & & $\mathbf{N}$ & $\%$ & & & \\
\hline Duktal & 5872 & 4391 & 74,8 & 95,3 & 86,4 & 74,9 \\
\hline Lobüler & 531 & 366 & 68,9 & 94,3 & 84,8 & 69,9 \\
\hline Kribriform & 123 & 107 & 87,0 & 100,0 & 98,3 & 93,5 \\
\hline İnflamatuar & 203 & 82 & 40,4 & 84,2 & 57,7 & 42,2 \\
\hline Medüller & 160 & 127 & 79,4 & 95,6 & 91,1 & 85,2 \\
\hline Tübüler & 32 & 27 & 84,4 & 100,0 & 100,0 & 96,0 \\
\hline $\begin{array}{l}\text { Glikojenden } \\
\text { zengin }\end{array}$ & 124 & 101 & 81,5 & 99,2 & 91,8 & 81,4 \\
\hline Miks & 1713 & 1337 & 78,1 & 96,1 & 88,1 & 76,2 \\
\hline Diğer & 1577 & 1047 & 66,4 & 90,3 & 79,5 & 65,4 \\
\hline \multicolumn{7}{|c|}{ Overall Comparisons } \\
\hline $\begin{array}{l}\text { Wilcoxon } \\
\text { (Gehan) }\end{array}$ & $\mathrm{df}$ & Sig. & & & & \\
\hline Statistic & & & & & & \\
\hline 265,057 & 8 &, 000 & & & & \\
\hline
\end{tabular}

Tablo-3. Evrelere göre sağ kalım.

\begin{tabular}{lllll}
\hline \multirow{2}{*}{ Evre } & $\mathbf{n}$ & \multicolumn{2}{c}{ Yaşayan } & \multicolumn{2}{c}{ 5 Yıl GSK 10 Yıl GSK } \\
& & $\%$ & $\%$ & $\%$ \\
\hline İnsitu & 425 & 94,6 & 97,2 & 94,6 \\
Lokalize evre & 3483 & 86,0 & 94,1 & 86,6 \\
Lokal ileri evre & 4168 & 71,3 & 85,5 & 71,1 \\
Metastatik evre & 698 & 32,5 & 39,1 & 22,7 \\
\hline
\end{tabular}


Erkek meme kanserlerinde GSK'nin kadın hastalara göre daha kötü olması dikkat çekicidir. Kadınlarda beş ve 10 yıllık sağ kalımlar \%85,4 ve $\% 77,4$ olarak saptanırken erkeklerde bu oranlar $\% 74,3$ ve \%63'e düşmektedir (Tablo-4, Şekil-10).

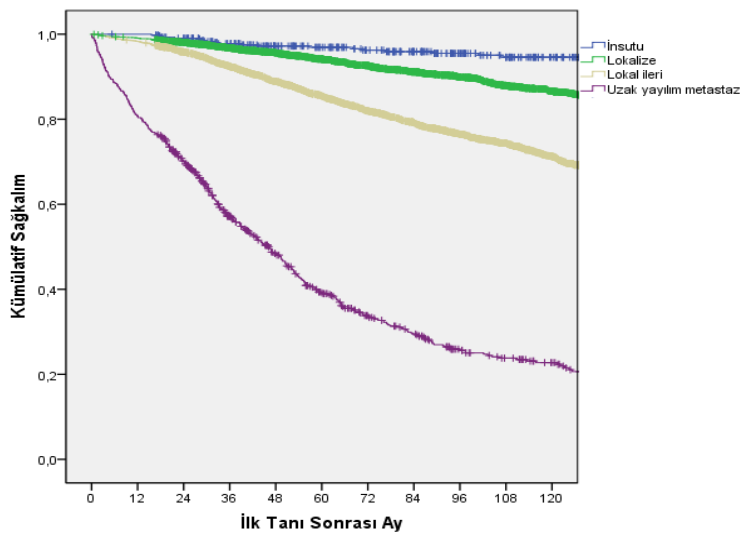

Şekil-9. Evrelere göre sağ kalım grafiği.

Tablo-4. Cinsiyete göre genel sağ kalım oranları.

\begin{tabular}{lllll}
\hline Cinsiyet & $\mathbf{n}$ & $\begin{array}{l}\text { Yaşayan } \\
\%\end{array}$ & $\begin{array}{l}\text { 5 Yıl GSK } \\
\%\end{array}$ & $\begin{array}{l}\text { 10 Yıl } \\
\text { GSK } \\
\%\end{array}$ \\
\hline Erkek & 119 & 56,3 & 74,3 & 63,0 \\
Kadın & 10216 & 73,6 & 85,4 & 77,4 \\
\hline
\end{tabular}

Yapılan tedavilere ve evrelere göre sağ kalımların değerlendirilmesinde ret veya medikal medikal nedenlerle hiç tedavi olmayanlara göre kombine adjuvan tedavilerin yapılması her evrede ayni anlamlııkta sağ kalıma katkıda bulunmaktadır $(p<0,0001)$ (Tablo-5, Şekil-11).

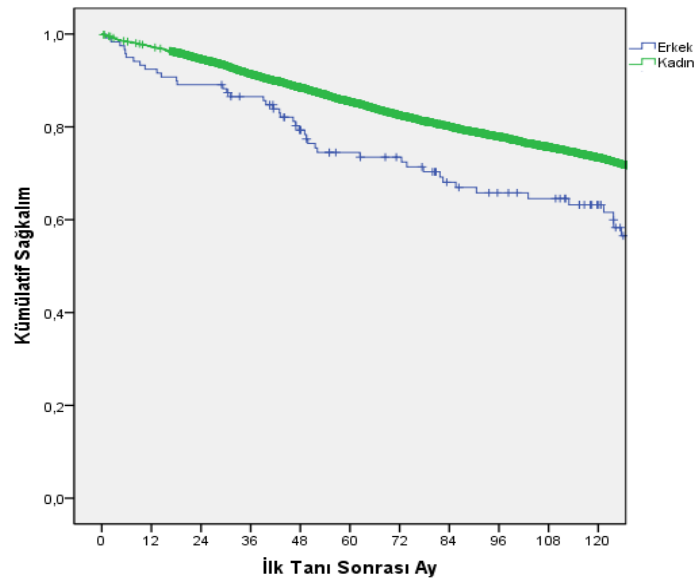

Şekil-10. Cinsiyete göre genel sağ kalım oranları.

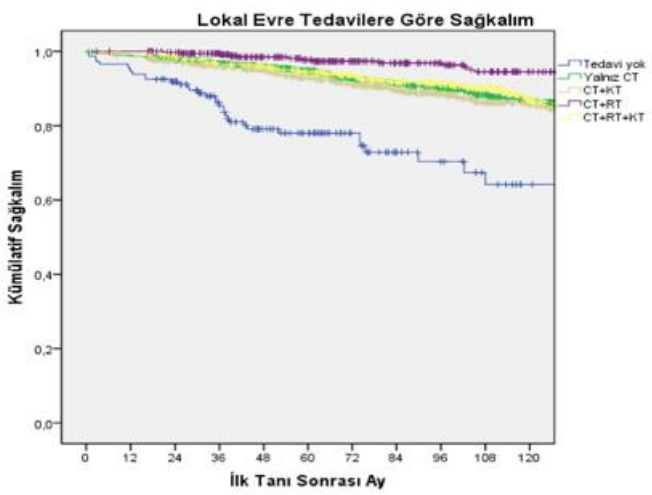

a

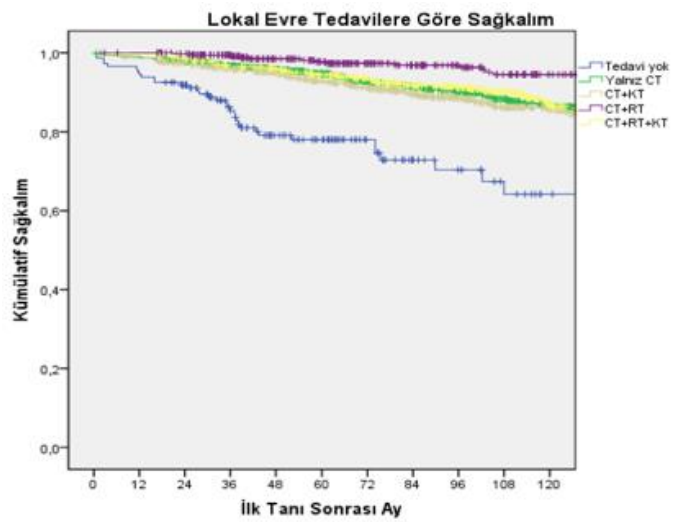

b

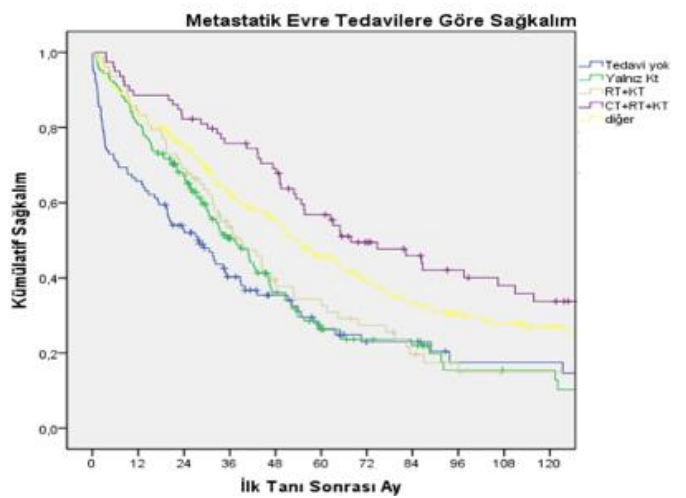

C

Şekil-11. Evrelere ve Tedavilere göre sağ kalım grafiği.
a. Lokal evre
b. Lokal ileri evre
c. Metastatik evre

Hormonoterapi uygulanan ve uygulanmayan olguların sağ kalımları karşılaştırıldığında özellikle lokal ileri evrede endokrin tedavi alan hastalarda sağ kalım avantajı dikkat çekicidir (Tablo-6). 
Tablo-5. Evrelere ve tedavilere göre sağ kalım.

a. Lokal evre meme kanserlerinde tedavilere göre sağ kalım.

\begin{tabular}{|c|c|c|c|c|c|}
\hline \multirow{2}{*}{ Tedavi } & \multicolumn{3}{|c|}{ Yaşayan } & \multirow[b]{2}{*}{5 yıl } & \multirow[b]{2}{*}{$10 \mathrm{yıl}$} \\
\hline & $\mathbf{N}$ & $\mathbf{N}$ & $\%$ & & \\
\hline Tedavi Yok & 147 & 112 & 76,2 & 77,9 & 63,2 \\
\hline Yalnız C & 1095 & 913 & 83,4 & 94,7 & 86,7 \\
\hline $\mathrm{C}+\mathrm{HT}$ & 93 & 75 & 80,6 & 93,2 & 84,3 \\
\hline $\mathrm{C}+\mathrm{RT}$ & 629 & 539 & 85,7 & 92,9 & 85,8 \\
\hline $\mathrm{C}+\mathrm{RT}+\mathrm{HT}$ & 130 & 115 & 88,5 & 96,6 & 86,1 \\
\hline $\mathrm{C}+\mathrm{KT}$ & 374 & 345 & 92,2 & 97,7 & 94,5 \\
\hline $\mathrm{C}+\mathrm{KT}+\mathrm{HT}$ & 217 & 203 & 93,5 & 98,9 & 94,2 \\
\hline $\mathrm{C}+\mathrm{RT}+\mathrm{KT}$ & 481 & 416 & 86,5 & 94,3 & 86,9 \\
\hline $\mathrm{C}+\mathrm{RT}+\mathrm{KT}+\mathrm{HT}$ & 255 & 230 & 90,2 & 95,4 & 87,3 \\
\hline \multicolumn{6}{|c|}{ Wilcoxon (Gehan) = 82,824 $p<0.0001$} \\
\hline
\end{tabular}

b. Lokal ileri evre meme kanserlerinde tedavilere göre sağ kalım.

\begin{tabular}{llllll}
\hline Tedavi & $\mathbf{N}$ & $\mathbf{N}$ & $\mathbf{\%}$ & $\mathbf{5}$ yıl & $\mathbf{1 0}$ yıl \\
\hline Tedavi Yok & 108 & 64 & 59,3 & 58,7 & 47,3 \\
Yalnız C & 865 & 592 & 68,4 & 86,6 & 74,7 \\
C+HT & 34 & 23 & 67,6 & 88,0 & 74,3 \\
C+RT & 844 & 637 & 75,5 & 86,5 & 72,2 \\
C+RT+HT & 106 & 83 & 78,3 & 87,4 & 72,9 \\
C+KT & 214 & 148 & 69,2 & 88,9 & 76,8 \\
C+KT+HT & 59 & 43 & 72,9 & 94,9 & 65,7 \\
C+RT+KT & 1166 & 772 & 66,2 & 83,8 & 66,5 \\
C+RT+KT+HT & 669 & 545 & 81,5 & 90,2 & 78,9 \\
Wilcoxon (Gehan) $=\mathbf{8 4 , 1 4 2} \mathbf{p}<\mathbf{0 . 0 0 0 1}$ & & & &
\end{tabular}

c. Metastatik evre meme kanserlerinde tedavilere göre sağ kalım.

\begin{tabular}{llllll}
\hline Tedavi & $\mathbf{N}$ & $\mathbf{N}$ & $\mathbf{0}$ & $\mathbf{5}$ yıl & $\mathbf{1 0}$ yıl \\
\hline Tedavi Yok & 111 & 31 & 27,9 & 26,5 & 18,1 \\
Yalnız C & 89 & 29 & 32,6 & 42,2 & 26,4 \\
C+HT & 4 & 1 & 25,0 & 25,0 & 25,0 \\
C+RT & 99 & 38 & 38,4 & 47,0 & 28,6 \\
C+RT+HT & 9 & 5 & 55,6 & 66,7 & 51,9 \\
C+KT & 16 & 2 & 12,5 & 21,4 & - \\
C+KT+HT & 4 & 2 & 50,0 & 75,0 & 75,0 \\
C+RT+KT & 79 & 31 & 39,2 & 57,0 & 33,9 \\
C+RT+KT+HT & 28 & 14 & 50,0 & 69,4 & 41,7 \\
Wilcoxon (Gehan) $=\mathbf{4 6 , 9 8 6 9} \mathbf{p}<\mathbf{0 . 0 0 0 1}$ & & & & \\
\hline
\end{tabular}


Tablo-6. Evrelere ve hormon tedavisine göre sağ kalım.

\begin{tabular}{|c|c|c|c|c|c|c|}
\hline Evre & HT & $\mathbf{N}$ & \multicolumn{2}{|c|}{ Yaşayan } & $\begin{array}{l}5 \text { yıl } \\
\%\end{array}$ & $\begin{array}{l}10 \mathrm{yll} \\
\%\end{array}$ \\
\hline \multirow{2}{*}{ Lokal Evre } & HT yok & 2629 & 2248 & 89,7 & 94,3 & 87,1 \\
\hline & HT+ & 707 & 634 & 85,5 & 96,3 & 88,6 \\
\hline \multirow{2}{*}{ Lokal İleri } & HT yok & 3183 & 2207 & 69,3 & 85,1 & 70,4 \\
\hline & HT+ & 877 & 699 & 79,7 & 90,0 & 76,7 \\
\hline \multirow{2}{*}{ Metastatik } & HT yok & 527 & 174 & 33,0 & 40,1 & 22,6 \\
\hline & $\mathrm{HT}+$ & 60 & 22 & 36,7 & 51,9 & 32,8 \\
\hline \multicolumn{2}{|c|}{ Second-order Controls } & \multicolumn{2}{|c|}{ Wilcoxon (Gehan) } & df & Sig. & \\
\hline \multicolumn{2}{|l|}{ Lokal } & \multicolumn{2}{|l|}{3,908} & 1 & ,048 & \\
\hline \multicolumn{2}{|l|}{ Lokal İleri } & \multicolumn{2}{|c|}{16,295} & 1 &, 000 & \\
\hline \multicolumn{2}{|l|}{ Metastatik } & \multicolumn{2}{|l|}{1,574} & 1 & ,210 & \\
\hline
\end{tabular}

\section{Tartışma}

Meme Kanseri kadınlarda en sık görülen kanser türü olup, Globacan istatistiklerine göre dünya genelinde kanser tanısı alan 4 kadından birinin meme kanseri olduğu söylenmektedir ${ }^{1}$. Bizim serimizde de kadın kanserlerinin \%25,2 sini meme kanserlerinin oluşturduğu görülmektedir. Tüm meme kanserlerinin \%1 ini erkek meme kanserleri oluşturur $(6,7)$. Bizim çalışmamızda ise erkeklerde meme kanserlerinin görülüşü tüm meme kanserleri içinde \%1,3'ünü kapsamaktadır. Olgularımızın en sık görüldüğü yaşlar kadınlarda 40-49 yaş aralığında olup bu bulgumuz kaynaklarla uygunluk göstermektedir (4).

Meme kanseri birçok gelişmiş ülkede yaygın tarama yöntemleri ve toplumsal bilinç sayesinde erken evrelerde yakalanan bir kanser türü olarak yer alırken maalesef bizim olgularımızda hala ilk tanı anında hastalarımız lokal ileri evrededir. Yirmi beş yıllık serimizde yıllara göre değerlendirme yapıldığında giderek erken evrelerde yakalanmanın artması ise sevindiricidir. Cinsiyete göre karşılaştırma yapacak olursak, kadın olguların tanı sırasında erkeklere göre daha erken evrelerde tanı almaktadır. Bu durumu kadınlara yönelik meme kanseri farkındalık programlarının yaygınlaşması olarak izah edebiliriz.

MK görülme hızı özellikle gelişmekte olan ülkelerde artış göstermektedir (1-3). Bizim serimizde de bu artış saptanmıştır. Özellikle son 10 yılda, pek çok gelişmiş ülkede menopozda HRT kullanımının azalmasına, emzirme sürelerinin uzamasına bağlı olarak düşme eğilimi gösterdiği gözlenmektedir. Bu durum risk faktörleri dikkate alınarak meme kanserinde korunma sağlanabileceğine işaret etmektedir.

Hastanemiz verilerinde saptadığımız sağ kalım oranları kaynaklarla uyum göstermektedir. Evrelere göre beş ve 10 yıllık genel sağ kalımlar sırasıyla; Lokalize kanserlerde \%94,1 ve \%86,6, lokal ileri evrede ise $\% 85,5$ ve $\% 71,1$, metastatik dönemde ise \%39,1 ve \%22,7'dir (Tablo-2, Şekil7). Erkek meme kanserlerinin hem daha ileri evrelerde tanı alması hem de sağ kalımların daha kötü olması dikkat çekicidir. Kadınlarda beş ve 10 yıllık genel sağ kalımlar \%85,4 ve \%77,4 iken erkeklerde bu oranlar \%74,3 ve \%63'e düşmektedir. Erkeklerde tanı esnasındaki ortalama yaşın daha ileri olması, bu hastalarda eşlik eden komorbid durumlara bağlı da genel sağ kalım oranlarını olumsuz etkilemiş olabilir.

Histopatolojik tanıya göre sağ kalımlar kaynaklara uygun olarak inflamatuar kanserlerde en kötü, tubuler kanserlerde en iyidir (8). Chen ve arkadaşları, SEER toplum tabanlı veri tabanında meme kanserinde metastatik evrede iki yıllık sağ kalımı \%60,9-39,9 arası bulmuşlardır. Metastatik evrede en iyi sağ kalım avantajı 50 yaş altı olgulardadır $(p<0,001)(9)$. Cerrahi ve radyoterapi lokal tedavi yöntemleri olarak bilinmekle beraber sağ kalım avantajına katkıda bulunmaktadır $(p<0.001)$ (9). Bizim serimizde de cerrahi ve radyoterapi sağ kalıma katkıda bulunmaktadır. Metastatik evrede iki yıllık sağ kalımlar \%40,4\%75,9 arası değişmektedir. Cerrahi, radyoterapi ve kemoterapi uygulanan metastatik meme kanserlerinde en iyi sağ kalım bulunmuştur $(p<0,0001)$. Meme kanserinde hormon duyarlı olgularda hormon tedavisi rutin kullanımımızda olan bir uygulamadır. 


\section{Sonuç}

EÜ Hastane Tabanlı Kanser Kayıt sistemindeki kadın kanserlerinin dörtte biri meme kanseridir. EÜH veri tabanındaki 13079 olgu içeren meme kanseri serisi tek merkezli olarak, ülkemizdeki en geniş meme kanseri serisidir. Olgularımızın en sık görüldüğü yaşlar kadınlarda 40-49 yaş, erkek olgularda ise 60-69 yaş aralığındadır. Yıllara göre MK görülme hızının hastanemizde arttığı saptanmıştır. Kadın olgularımızda erkeklere göre daha erken evrelerde tanı konmakta ve prognoz daha iyi olmaktadır. GSK; 40-49 yaş grubunda, kribriform histolojide ve erken evrelerde daha iyidir. Erkek meme kanserlerinde GSK kadın hastalara göre daha kötüdür. Metastatik evrede kemoterapiye cerrahi ve radyoterapi ilavesi sağ kalım avantajı sağlamaktadır.

Teşekkür: Bu çalışma 1992den itibaren 25 yıllık olguları kapsamaktadır. Bu süre içinde hasta alımında emekleri geçen Genel Cerrahi AD Meme hastalıkları bölümü öğretim üyeleri Prof. Dr. Orhan Özbal'a, Prof. Dr. Rasih Yılmaz'a ve Prof. Dr. Murat Kapkaç'a, rahmetli hocamız Prof. Dr. Emin Özdedeli'ye, istatistik analizleri yapan EUKAM bilgisayar ve istatistik uzmanı Ömer Karaca'ya, EÜKAM kanser kayıt elemanlarına teşekkürü borç biliriz.

\section{Kaynaklar}

1. Bray F, Ferlay J, Soerjomataram I and et al. Global Cancer Statistics 2018: GLOBOCAN Estimates of Incidence and Mortality Worldwide for 36 Cancers in 185 Countries. Cancer J Clin. 2018; 68: 394-424.

2. Héry $C$, Ferlay J, Boniol M, Autier P. Changes in breast cancer incidence and mortality in middle-aged and elderly women in 28 coun- tries with Caucasian majority populations. Ann Oncol 2008; 19 (6): 1187-94.

3. Ravdin PM, Cronin KA, Howlader N, Berg CD, Chlebowski RT, et al. The decrease in breast-cancer incidence in 2003 in the United States. N Engl J Med. 2007 Apr 19; 356 (16): 1670-4.

4. Key TJ, Verkasalo PK, Banks E. Epidemiology of breast cancer. Lancet Oncol 2001; 2 (3): 133-40.

5. Haydaroğlu A, Dubova S, Ozsaran Z, Bolukbaşı Y, et al. Ege Üniversitesinde Meme Kanserleri: 3897 Olgunun Değerlendirilmesi. Meme Sağı̆ğı Dergisi 2005; 1 (1): 6-11.

6. Abdelwahab Yousef AJ. Male Breast Cancer: Epidemiology and Risk Factors. Semin Oncol. 2017 Aug;44(4):26772.

7. Çakar B, Sert F, Gürsoy P, Emekdaş B, Özsaran Z, Gökmen E, Haydaroğlu A. Long-Term Follow-Up of Patients with Male Breast Cancer, Single-Center Experience. Turk J Oncol 2019; 34 (2): 66-71.

8. Li Cl. Risk of mortality by histologic type of breast cancer in the United States. Horm Cancer. 2010 Jun;1 (3): 156-65.

9. Chen MT, Sun HF, Zhao $Y$ et al. Comparison of patterns and prognosis among distant metastatic breast cancer patients by age groups: a SEER population-based analysis. Sci Rep. 2017 Aug 23; 7 (1): 9254. 